\title{
ROBUST CLASSIFICATION OF TEXTURE LAND FOREST INVENTORY BASED ON MODEL OF MINIMALLY SUFFICIENT FEATURES
}

Yury Ipatov*

Volga State University of Technology, Yoshkar-Ola, Russia

Alexandr Krevetsky

Volga State University of Technology, Yoshkar-Ola, Russia

Yury Andrianov

Volga State University of Technology, Yoshkar-Ola, Russia

Boris Sokolov

Saint Petersburg Institute of Informatics and Automation, Russian Academy of Sciences (SPIIRAS), Saint Petersburg, Russia

Method for automated classification of ground forest inventory images based on the proposed mathematical model developed. The general model is represented by the statistical characteristics of images and fractal dimension of texture. Experimental means were determined minimally sufficient characteristics to solve the problem of robust classification. Neural network based on unsupervised self-organizing maps used as a classifier. Figures obtained discounts of the proposed approach on real digital images.

Key words: Image classification, Image model, Statistical characteristics, Fractal dimension of the scene, Neural network without a teacher

\section{INTRODUCTION}

Modern approaches in the field of forest inventory, ecological monitoring, estimation and prediction of bio resources can be conditionally divided into two scientific and technical areas: the first is connected with the analysis of small-scale (remote sensing data of the earth, aerial photography) and the second large-scale (images on the terrain) images. For the first direction, automated solutions are created and widely used in practice - hardware and software that implement digital image processing and pattern recognition techniques [01,02]. At the same time, important mass ground-based measurements, in particular for dendrochronology, studies of the soil fertility dynamics, analysis of the illumination for the forests lower tier, measurement of the specific volume for plant cover biomass, specific volume of technological wood, are now performed by manual, labor-intensive visual methods, have high cost and large time costs.

For the classes of scenes typical for the above tasks, it was possible to create automated soft- ware and hardware complexes that reduce the complexity of taxation by one or two orders of magnitude [03-05]. The next important step in increasing the effectiveness of integrated terrestrial inventory is the automation sorting of registered images, their preparation for the use of adequate algorithms and the final systematization results of the image analysis algorithms based on the classification of scenes.

The analysis of publications in the field of image classification shows that this direction develops in information systems by different levels of complexity. So there are methods based on extracting from the texture of the spectrum-signatures [08] and wavelet-signatures [09], invariant to the rotation, and in some cases also to the scale. The accuracy of these methods varies from $60 \%$ to $90 \%$ of the correct classification for different observation conditions. Texture analysis of images based on second-order statistics [10] gives high correct classification and an average of $90 \%$ [11]. Methods that use color information as attributes $[12,13]$ are characterized by better results on a large class of images, where the cor 
rect classification is from $80 \%$ to $100 \%$.

In this paper, we propose a method for automated classification of characteristic types of terrestrial forest inventory scenarios, which makes it possible to combine individual scientific and technical solutions into a single complex. Due to this, to minimize the operator's work both at the stage of registering images in a single database, and when preparing images for intelligent processing and fixing its results.

\section{STATEMENT OF THE PROBLEM}

Schematically, the space for spatial registration of the given image classes is shown in Figure 1 , where the point of image registration. The first class of images (trunks of trees on promising types of forest tracts) is registered along this direction $\mathbf{H A D D}_{\mathbf{1}} \mathbf{A}_{\mathbf{1}}$, the second class of images (leaf cover of plants of a certain type) - GADD $\mathbf{A}_{\mathbf{1}}$ and the third class (tree crowns of

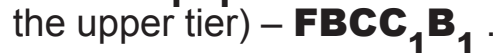

Detailed analysis and experimental studies of statistical, correlation and spectral characteristics of the three classes of images were carried out earlier, and key parameters and regularities were found which allowed constructing mathematical models of images and algorithms for their analysis [03-07].

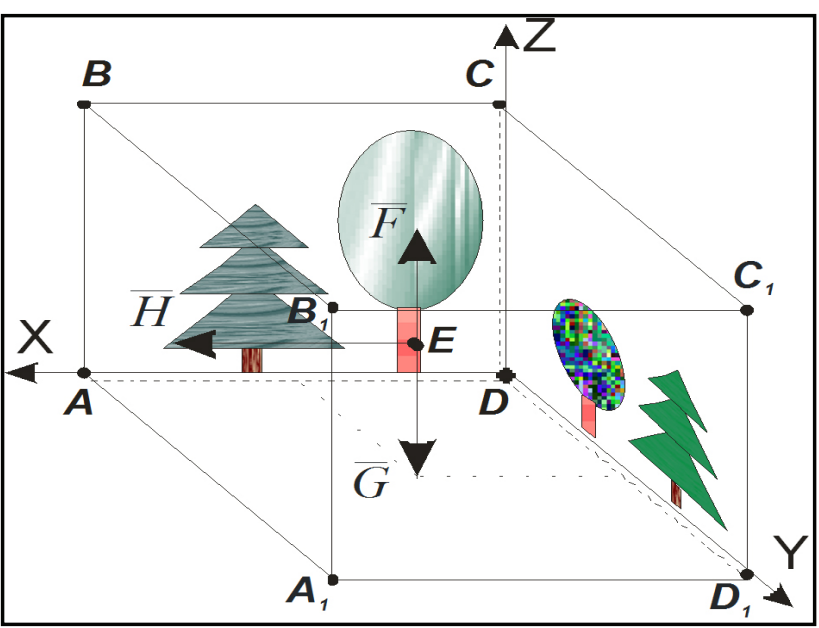

Figure 1. Scheme of the image registration area for terrestrial forest inventory

Based on the results of a comparative analysis for the characteristics of digital images by the three classes of scenes, informative features were selected that can be used to classify the observed images. The question of choosing the minimum sufficient number of such features re- quires detailed study and practical tests on the existing class of scenes.

\section{SOLUTION METHOD}

As statistical characteristics for the creation of the secondary scene description, $x$ the arithmetic mean of the image brightness $I(x, y)$, as well as its variance and the standard deviation $\sigma$, were determined, the value of the coefficient of variation, which is a relative measure of dispersion expressed as a percentage:

$$
v=\frac{\sigma}{x} \cdot 100 \%
$$

When investigating the brightness distribution shape of single image, the degree of asymmetry and kurtosis of the distribution are estimated. Symmetric is the distribution in which the frequencies of two equidistant characteristic values are equal to each other. The degree of asymmetry of the distribution in its central part is determined using the Pearson's asymmetry coefficient:

$A s=\left(\sum_{i=1}^{m}\left(x_{i}-\bar{x}\right)^{3} * n_{i}\right) \times\left(\sigma^{3} \sum_{i=1}^{m} n_{i}\right)^{-1}$

The kurtosis index is calculated by the formula:

$$
E x=\left(\sum_{i=1}^{m}\left(x_{i}-\bar{x}\right)^{4} * n_{i}\right) \times\left(\sigma^{4} \sum_{i=1}^{m} n_{i}\right)^{-1}-3
$$

if $E x>0$, then the distribution refers to sharp top and at $<0$ distribution refers to flat top.

Ideally, the introduction of a new independent measurement in the feature space increases the distance between the points of the feature space by an average of $\sqrt{2}$ times[14].

New attributes can be obtained by producing various image transformations, measuring various statistical moments and so on. However, the introduction of all new measurements is meaningful only up to a certain value determined by the fractal dimension of the image, after which the distance between the images does not change [14]. To obtain a new discriminating feature of the images (Figure 2, a-c), it is expedient to calculate their fractal dimensions.

The fractal dimension of objects is conveniently measured by changing a certain image parameter at different scales. In practice, the fractal di- 

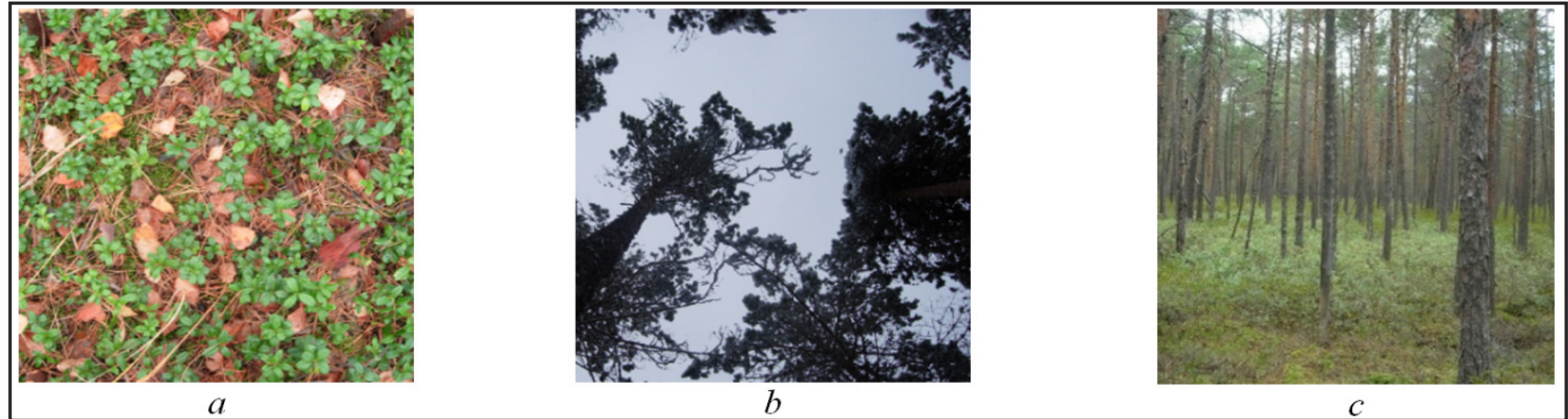

Figure 2. Inventory images: a - projective cover, $b$ - crown skylight, $c$ - tree stand

mension is measured indirectly from the slope of the dependence $S=S(d)$, where $S$ - measured value, $d$ - measuring step.

For a fractal object, the quantity is described by formula:

$$
S(d)=k d^{-D}
$$

where $k$-coefficient of proportionality. To estimate the fractal dimension $[02,14]$ of the image, we obtain a two-dimensional power spec- trum for the studied image region averaged over the azimuth. Such a spectrum is called a one-dimensional radial power spectrum of the image. The constant frequency component is excluded from the analysis. The resulting radial power spectrum is transformed to a double logarithmic scale, and then we find a linear approximating function.

In Figure 3. the radial power spectra of the survey images are shown in a double logarithmic scale.
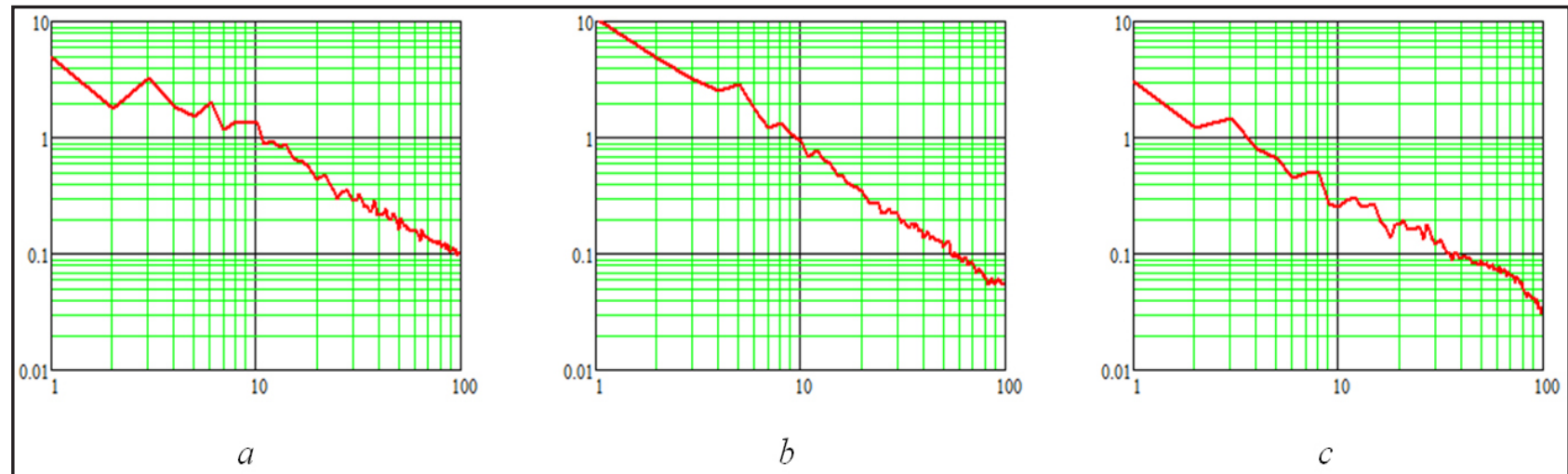

Figure 3. Radial power spectra of the taxation images: a - projective cover, $b$ - crown skylight, $c$ - aperiodic textures

The fractal dimension $D$ is determined from the slope of the function found using the following relation:

$$
D=2,5-s / 2
$$

where s - slope of the straight line, approximating the data converted to a double logarithmic scale.

The obtained values of the fractal dimension for the different values in taxation images by square fragments (windows) are presented in Table.

The mathematical model of a digital image $I(x, y)$ in our case can be described by expression: .
To reduce the complexity of the algorithm for classifying scenes without a noticeable decrease in the quality of decisions, it is advisable to estimate the minimum sufficient number of elements for model $\mathbf{S}$.

At the same time, the criterion of the quality for selection will be:

$$
\hat{\eta}=\operatorname{argmin}(\bar{S}=\{i, i+1, \ldots, i+j\})
$$


Table 1: The obtained values of the fractal dimension for the different values in taxation images by square fragments (windows)

\begin{tabular}{|c|c|c|c|c|}
\hline Type of taxation image & \multicolumn{4}{|c|}{ Window size } \\
\hline & $50 \times 50$ & $100 \times 100$ & $200 \times 200$ & $500 \times 500$ \\
\hline Projective cover & $2,88-3,16$ & $2,90-3,11$ & $2,90-3,03$ & $2,92-3,01$ \\
\hline Crown skylight & $3,09-3,36$ & $3,10-3,39$ & $3,16-3,37$ & $3,24-3,35$ \\
\hline Aperiodic textures & $3,09-3,34$ & $3,15-3,31$ & $3,29-3,12$ & $3,15-3,23$ \\
\hline
\end{tabular}

\section{CLASSIFICATION MODEL}

To separate the independent classes of images, we will use learning without control based on the principles of Kohonen's self-organizing network [15]. The architecture of such a network is presented in Figure 4.

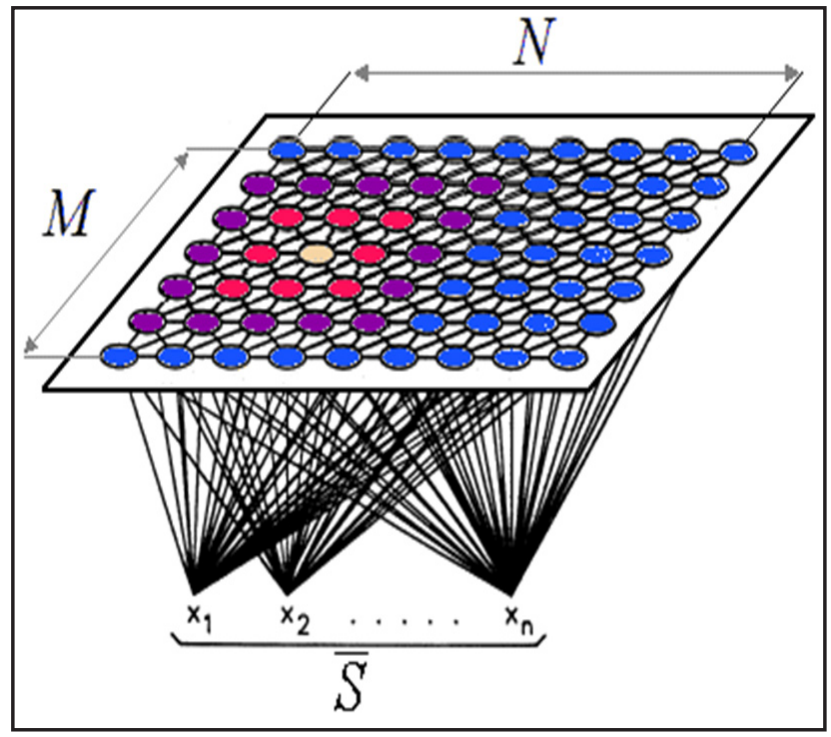

Figure 4. Basic architecture of the network for self-organizing attribute maps

Input elements of the vector are intended for the distribution of data between the input elements of the network. Cluster elements (output) are represented as a two-dimensional array .

In the course of training, the element of the impulse is determined, for which the square of the Euclidean distance to the learning vector:

$$
d_{p q}=\sum_{i}^{n}\left(x_{p i}-x_{q i}\right)^{2}
$$

where $d_{p q}$ - square of the Euclidean distance between points $p$ and $q, x_{p i}$ - coordinate of the image $p$ (similarly for the image $q$ ) and $n$-dimension value.

A cluster will be a group of vectors, the distance between which inside this group is less than the distance to neighboring groups. The structure of clusters using the SOM algorithm can be displayed by visualizing the distance between the reference vectors (neuronal weights) [16].

\section{RESULTS OF WORK}

For approbation of the proposed method of classification of typical inventory scenes, a sample of 60 digital images $\left(\Omega_{1}\right) 800 \times 600$ was created, where each class of scenes was represented in equal measure.

To estimate the number of indicators in a mathematical model of an image, one can use an expression for calculating the number of combinations $\mathrm{C}_{\mathrm{n}}{ }^{\mathrm{k}}$ :

$$
C_{n}^{k}=\frac{n !}{k !(n-k) !}
$$

where $n$ - set of elements for the model $S$ and $k$ - set of selected data $\mathbf{k} \mathbf{n}$. Next, we estimate (6) the model $S$ for every possible number of combinations (8).

Table 2 shows the overall value of the combinations when the parameter is changed, as well as the number of experimentally tested models. The discrepancy between these values can be explained by the fact that only those models that maximally reflect the given class of images in the attribute space were taken for verification.

Table 2: The overall value of the combinations when the parameter is changed

\begin{tabular}{|c|c|c|c|c|c|c|}
\hline & $\mathrm{C}_{7}^{3}$ & $\mathrm{C}_{7}^{4}$ & $\mathrm{C}_{7}^{5}$ & $\mathrm{C}_{7}^{6}$ & $\mathrm{C}_{7}^{7}$ & Total \\
\hline $\begin{array}{c}\text { Possible } \\
\text { values }\end{array}$ & 35 & 35 & 21 & 7 & 1 & 99 \\
\hline $\begin{array}{c}\text { Experi- } \\
\text { mentally } \\
\text { verified }\end{array}$ & 3 & 7 & 11 & 7 & 1 & 29 \\
\hline
\end{tabular}


Of all models, only those are selected for which the error of the first and second kind has the smallest value [17]. As a result, we obtain models $\overline{S_{1}}=\left\{\mathrm{s}^{2}, \mathrm{n}, A s, E x, D\right\}, \overline{S_{2}}=\left\{\mathrm{s}, \mathrm{s}^{2}, \mathrm{n}, A s, D\right\}$ and $\quad \overline{S_{3}}=\left\{s^{2}, \mathrm{n}, A s, E x, D\right\}$, for which the mean error of the first kind is $F_{1}=0,06$ and error of the second kind is $M_{1}=0,08$.

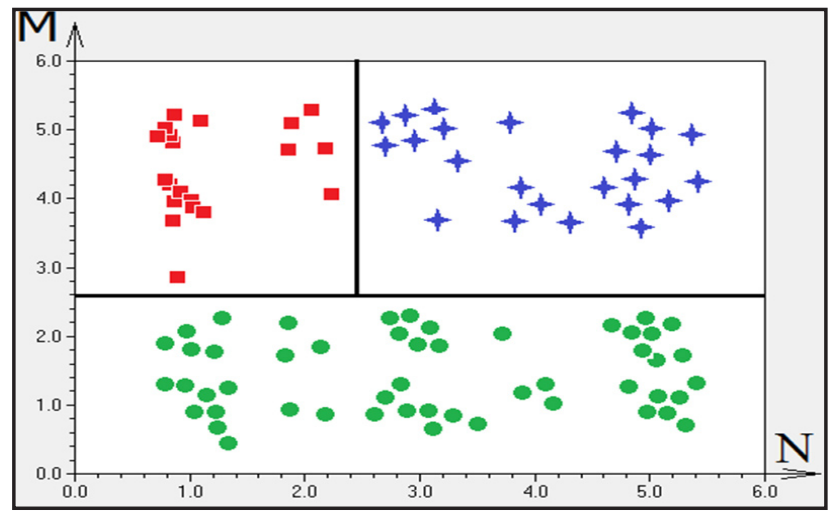

Figure 5. The results of dividing the three types of images on the self-organization map without a teacher

To test the models $\mathrm{S}_{1}, \mathrm{~S}_{2}, \mathrm{~S}_{3}, \mathrm{~S}_{4}$, a test sample $\left(\Omega_{2}\right)$ of 95 images was created, where the proportion of the first class of images was $25 \%$, the second class $-20 \%$, and the third class $-55 \%$. In Figure 5 shows the best result for the criterion of the minimum mean error of the first and second kind for the model $\mathbf{S}_{\mathbf{4}}$.

The work of the self-organizing network was carried out with the following parameters: the cluster elements had the dimension , the training speed, the initial range of the neighborhood, and the number of epochs $L=10000$.

\section{CONCLUSION}

Thus, as a result of statistical tests, the minimum sufficient parameters of the model describing images with secondary characteristics were determined for effective decisions on the quality and complexity of the classification of given types for taxation scenes. The proposed approach is tested on real digital images and has a minimal average classification error, which allows to split a series of such images in an automatic mode to solve the problems of terrestrial forest inventory. This work was supported by state order of the Ministry of Education and Science of the Russian Federation №2.3135.2017.

\section{REFERENCES}

1) John A. Richards, XiupingJia Remote Sensing Digital Image Analysis. - Berlin: Springer, 2006. - $454 \mathrm{p}$.

2) Schowengerdt RA. Remote Sensing - Models and Methods for Image Processing. 2nd ed. London, San Diego: Academic Press; 1997. ISBN: 0-12-628981-6.

3) Ipatov Y.A., Krevetsky A.V. Algoritm lokalizatsii granits teksturnykh uchastkov drevesiny na ikh tsifrovykh izobrazheniyakh // Izv. vuzov. Priborostroyeniye. 2009. Volume. 52, № 7. - pp. 12-17.

4) Ipatov Y.A., Krevetsky A.V. Segmentatsiya tsvetnykh aerofotosnimkov na osnove algoritma selektivnogo obucheniya// Vestnik MarGTU. Radiotekhnicheskiye i infokommunika-tsionnyye sistemy. - Yoshkar-Ola: MarGTU- №.2, 2008. - pp.22-26.

5) Krevetsky A.V., Ipatov Y.A. Kompleksirovannoye optiko-lokatsionnoye obnaruzheniye i otsenka parametrov obyektov nazemnoy lesnoy taksatsii// Uspekhi sovremennoy radioelektroniki. Radiotekhnika. - 2011. №5. - p. 56-60.

6) Ipatov Y.A. Process automation of an estimation for relative density of wood plantings the instrumentality of methods of digital image processing // 8-th International Conference «PRIA: New Information Technologies»: Conference Proceedings. Vol. 1. - YoshkarOla, 2007. - P.307-309.

7) Krevetsky A.V., Ipatov Y.A. High Technologies in Measuring Problems of Forestry Complex on The Basis of Scene Analysis and Image Recognition Method// 8-th International Conference «PRIA: New Information Technologies»: Conference Proceedings. Vol. 2. - Yoshkar-Ola, 2007. - P.287-289.

8) Novyye teksturnyye kharakteristiki i ikh ispol'zovaniye $v$ klassifikatsii tekstur, invariantnykh k izmeneniyu ugla povorota, DzhiangoZhang, TiyenuTan, 2001 [Elektronnyy resurs]. - Rezhim dostupa: http://lear.inrialpes.fr/people/zhang/ECCV_paper.pdf

9) Logarifmicheski-polyarnyye veyvlet-signatury dlya klassifikatsii tekstur, invariantnykh k vrashcheniyu i masshtabu, Chi-Men Pan, Mun-Chuyen Li, IEEE Transactionson Pattern Analysisand Machine Intelligence, vol. 25, no. 5, May 2003. 
1) R.M.Haralick, K.Shanmugam, I.Dinstein, Textural features for image classification // IEEE Trans.Syst.ManCybern. v.3, pp.610621, 1973.

2) N.Y. llyasova, A.V. Kupriyanov, A.G. Khramov, Klassifikatsiyakristallogrammsispol'zovaniyem metodov statisticheskogo analiza teksturnykh izobrazheniy // Komp'yuternaya optika, vyp. 20, pp. 122-127, 2000

3) Tkhi Tkhu Chang Buy, Ngok Khoang Fan, V. G. Spitsyn Klassifikatsiya izobrazheniy na osnove primeneniya tsvetovoy informatsii, veyvlet-preobrazovaniya khaara i mnogosloynoy neyronnoy seti // Problemy informatiki. - 2011. № 5. pp. 81-86.

4) A.V. Kuznetsov Klassifikatsiya izobrazheniy $\mathrm{s}$ ispol'zovaniyem yader na strukturirovanny- kh dannykh //Sb. nauchnykh trudov NGTU.2011. -№3(65) pp.55-60.

5) Potapov A. A., Pakhomov A. A., Nikitin S. A., Gulyayev YU. V., Noveyshiye metody obrabotki izobrazheniy. - M.: Fizmatlit, 2008.-496 p.

6) Khaykin S. Neyronnyye seti: polnyy kurs, 2ye. - M.: «Vilyams», 2006. - p. 1104.

7) TeuvoKohonen, "Self-Organizing Maps", Springer-Verlag, Heidelberg, 1995.

8) Korn G., Korn T. Handbook of Mathematics for Scientists and Engineers. M.: Nauka, 1984. - 832p.

Paper sent to revision: 18.05.2017.

Paper ready for publication: 26.06.2017. 